\title{
Development on V-N microalloyed forging steel used in fracture splitting connecting rods
}

\author{
Xianzhong Zhang ${ }^{\mathrm{a}}$, Yuzhang Xiong and Guifeng Zhou \\ R\&D Center Wuhan Steel and Iron (Group) Corp. Wuhan, Hubei, 430081, China
}

\begin{abstract}
A new type of high strength microalloyed forging steel used in fracture splitting connecting rods was developed. By chemical composition and process design, a network of ferrite and pearlite could obtain, it was benefit to fracture splitting. Compare with C70S6 which normally used in fracture splitting rods, the developed microalloyed steel was superior in mechanical properties and fatigue strength. Furthermore, the fracture splitting surface showed distinct brittle fracture character and favorable fracture splitting properties.
\end{abstract}

Keywords: microstructure; mechanical properties; fatigue strength; microalloyed forging steel; fracture splitting.

\section{Introduction}

Fracture splitting method for the automobile engine connecting rod is attracting attention as a new possible manufacturing method. It allows the connecting rod cap to be separated from the connecting rod such that the mating surfaces do not require machining. This saves numerous steps in the machining process. When the rod is attached to the crankshaft and the cap reattached with bolts, the mating surfaces join in what is almost a perfect joint at the atomic level. Therefore, compared with the traditional method, it is beneficial to cut down the working procedures, reduce the processing equipments and decrease the cost for producing connecting rods [1,2]. The materials used for fracture splitting connecting rods not only affect the tensile properties and machinability, but also decide the fracture splitting properties. Furthermore, the microstructures of fracture splitting connecting rods decide the fracture splitting technologies [3]. At present, the materials that can be used to make fracture splitting connecting rods are mainly the powder metallurgy materials and microalloyed high carbon steel. Compared with the powder metallurgy material, the microalloyed carbon steel can provide more excellent microstructure, mechanics property and high dimension precision. Therefore, they have been applied extensively in Europe and North America, and some microalloyed carbon steels such as SPLITASCO70 and SPLITASCO50 (France), S53CVFS and S50CVS1 (Japan) and C70S6BY (Germany), etc., have been developed and used in the production of fracture splitting connecting rods [4].

For microalloyed steels, high strength can be obtained by increasing the percentage distribution of pearlite, grain refining and precipitation strengthening. The objective of the present work is to develop a new high strength microalloyed forging steel to meet the demands of fracture splitting connecting rods.

a Corresponding author : zhangxianzh@163.com 


\section{Chemical composition design}

In general, the microalloyed steel used for automobile engine fracture splitting connecting rods requires high strength, low distortion, appropriate brittleness and high sulphur for improved machinability. These properties can be obtained by changing the chemical composition and processing.

Carbon is an element which is inexpensive and effective for ensuring hardness and strength of steel. Steel having a low percent of carbon content cannot achieve a desired strength. Meanwhile, a high percent of carbon content cause an excessive hardness which can degrade a cutting property and toughness of steel, and it is not benefit to improve the fatigue property of steel. Therefore, it is necessary to set the content of carbon at $0.35-0.40 \%$.

Vanadium is the main precipitation strengthening element in microallyed steel. It can be dissolved in the austenite and entirely participate in the precipitation strengthening phase when the steel is cooled to region of ferrite transformation. The studies $[5,6]$ indicate that it can increase strength over $250 \mathrm{MPa}$ when adding $0.10 \%$ content of vanadium to steel. Furthermore, vanadium reacts with nitrogen and carbon to form carbonitrides to increase the strength after forging, so as to exhibit the effect of improving an offset yield strength (the strength can be improved about 6MPa by adding $0.001 \%$ content of nitrogen). Additionally, carbonitrides of vanadium strengthen the ferritic phase to suppress deformation at the time of fracture, exhibit the effect of improving fracture separation ability [7]. Comparing with traditional $38 \mathrm{MnVS}$, the stress strength and yield strength of the development steel are above $1000 \mathrm{MPa}$ and $750 \mathrm{MPa}$ which are higher $200 \mathrm{MPa}$ than $38 \mathrm{MnVS}$, so that the vanadium content is set at $0.20 \%-0.30 \%$.

The complex precipitations of $\mathrm{V}(\mathrm{C}, \mathrm{N})$ not only strengthen the matrix, but also restrain the migration of austenite grain boundaries. Therefore, they can refine the ferrite grain and pearlite groups. Furthermore, the complex precipitations can be the nucleation core of ferrite and ferrite grain refinement. However, the nitrogen addition of a large amount results in formation of defect at the same time of continuous casting. The amount of nitrogen addition therefore is set within the range of from $0.010 \%$ to $0.015 \%$.

Sulfur is an element having the effect of forming sulfides with manganese and improving the cutting property. Furthermore, the fine sulfured manganese which the dissolve temperature is $1440^{\circ} \mathrm{C}$ can become the core of ferrite and fine the microstructure of ferrite and pearlite, so that the content of sulfur is desired at $0.030 \%-0.060 \%$.

Manganese and silicon are dissolve strengthening elements in microalloyes steel, they all have the effect of enhancing strength after forging to improve the hardenability, so it is set the contents such as Manganese:0.80-1.20\%, Silicon:0.50-0.70\%.

According to above analysis, desired a new type of strength V-N microalloyed steel with excellent machinability used for automobile engine fracture splitting connecting rods. The chemical composition is shown in Table 1.

Table 1. Chemical composition of steel used in fracture splitting connecting rod (wt $\%)$

\begin{tabular}{|c|c|c|c|c|c|c|}
\hline $\mathbf{C}$ & $\mathbf{S i}$ & $\mathbf{M n}$ & $\mathbf{V}$ & $\mathbf{N}$ & $\mathbf{P}$ & $\mathbf{S}$ \\
\hline $0.35-0.40$ & $0.50-0.70$ & $0.80-1.20$ & $0.20-0.30$ & $0.010-0.015$ & $\leq 0.035$ & $0.030-0.060$ \\
\hline
\end{tabular}

\section{Process design}

The processes of microalloyed steel include: steel making, continuous cast, rolling, forging and controlled cooling process.

Steel-making process: The steel is molten in a 70 tons Consteel electric arc furnace, refined in a 70 tons ladle furnace with heating and bottom blowing argon, finally, the molten steel is casted into billets by continuous casting equipments. some technologies are applied during steel-making process: 
(1) Adopting high basic oxidation foam slag and deviated bottom taping technology to lessen the mass fraction of inclusion and phosphorus in the molten steel; (2) In order to improve the reclaiming of [S] during the refining in the ladle furnace low basic deoxidization slag being applied, its chemistry composition is (wt\%): $40 \sim 45 \% \mathrm{CaO}, 15 \sim 20 \% \mathrm{SiO}_{2}, 15 \sim 20 \% \mathrm{Al}_{2} \mathrm{O}_{3}, 10 \sim 15 \% \mathrm{MgO}$, the rest is $\mathrm{FeO}$, $\mathrm{MnO}$, etc. (3) Enough ladle bottom blowing argon time before casting so as to improve the homogeneity of the composition and microstructure.

Hot-rolling process: (1) Adopting torsionless and tensionless high speed continuous rolling technology; (2) Applying controlled rolling process. In order to solute the complex V carbonitrides completely in the solidification steel, the reheating temperature is controlled strictly at $1200 \pm 20^{\circ} \mathrm{C}$ in the heating furnace. It is important to ensure all rolling steps are finished above the austenite recrystallization temperature during the tolling because it effects on the microstructure of the microalloyed steel.

Forging process: In order to get needing microstructure and mechanical properties, it is necessary to strictly control the forging temperature at $1230 \pm 10^{\circ} \mathrm{C}$ through the electric induction heating and cooling rate of $5 \pm 1^{\circ} \mathrm{C} / \mathrm{s}$ by air cooling. BY heat treatment is applied during forging, it is beneficial to refine the ferrite grain size and disperse the precipitated phases in the microalloyed steel.

\section{Microstructure and properties}

\subsection{Microstructure}

Fig. 1 showed the typical microstructure of hot-rolling and hot-forging microalloyed steel. As can be seen, the hot-rolling process produced pearlite and ferrite structure as the hot-forging process. However, the volume fracture of pearlite is less in hot-rolling process than in hot-forging process. And the ferrite grain size is much fine in hot-forging process.

BY heat treatment has affected the volume fraction of pearlite and finer grain size of ferrite. These effects are generally associated with the influence of cooling rates on the coalescence and growth rates of ferrite. When normal cooling rate was employed the grain growth took place before the $\gamma$ - to $\alpha$ transformation. The pro-eutectoid ferrite nucleates on austenite grain boundaries, and the room temperature microstructure consists of a coarse ferrite and pearlite. By contrast, By BY heat treatment only certain recrystallized grains could grow preferentially; thus mixed austenite grain sizes will appear before the $\gamma$ - to $\alpha$ - transformation. As a result, the microstructure will be formed by a network of ferrite grains of unequal size, as shown in Fig. $1 \mathrm{~b}$.

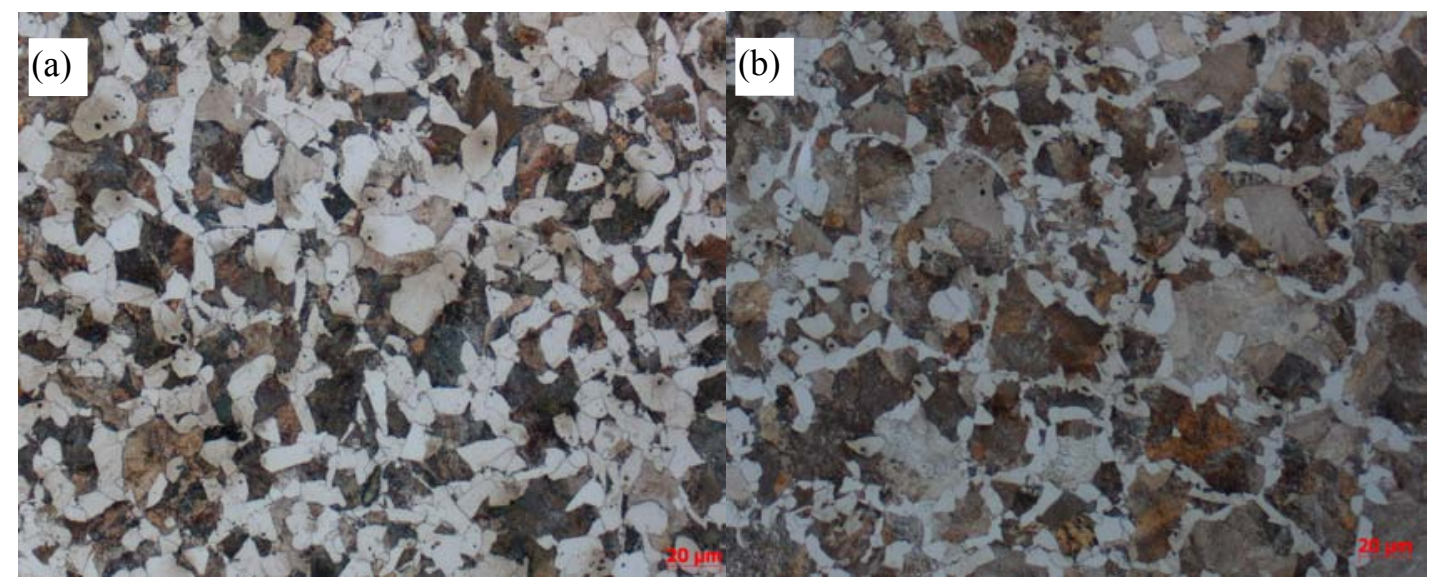

Figure 1. Microstructures of the V-N microalloyed steel with hot-rolling process and hot-forging process, (a) hot-rolling process, (b) hot-forging process 


\subsection{Mechanical properties}

The mechanical properties of developed steel and C70S6 steel were given in Table 2. As listed in Table 2, the developed steel showed higher YS, ultimate tensile strength (UTS), elongation, contraction of area and impact toughness than C70S6 steel. At the same time, the Yield Ratio (YS/UTS) also increased 13\% than C70S6 steel. Since high yield ratio is benefit to the properties of fracture splitting connecting rod.

Table 2. Mechanical properties of developed steel and C70S6 steel

\begin{tabular}{|c|c|c|c|c|c|c|}
\hline Steels & YS/MPa & UTS/MPa & $\begin{array}{c}\text { Yield } \\
\text { ratio/\% }\end{array}$ & $\begin{array}{c}\text { Reduction } \\
\text { of area/\% }\end{array}$ & Elongation/\% & $\begin{array}{c}\text { Impact energy } \\
\text { at } 20^{\circ} \mathrm{C} / \mathrm{J}\end{array}$ \\
\hline $\begin{array}{c}\text { Development } \\
\text { steel }\end{array}$ & 765 & 1100 & 70 & 18 & 35 & 42 \\
\hline C70S6 & 565 & 950 & 60 & 10 & 20 & 10 \\
\hline
\end{tabular}

\subsection{Fatigue strength}

Fig. 2 shows the results of the rotating fatigue test of each specimen. The fatigue limit of the specimen was reached after $10^{7}$ cycles. The fatigue limit of C70S6 steel was $350 \mathrm{MPa}$, and $400 \mathrm{MPa}$ for the developed steel, which was $20 \%$ higher than that of C70S6. Therefore, it can be concluded that the developed steel for the fracture splitting connecting rods has high fatigue strength.

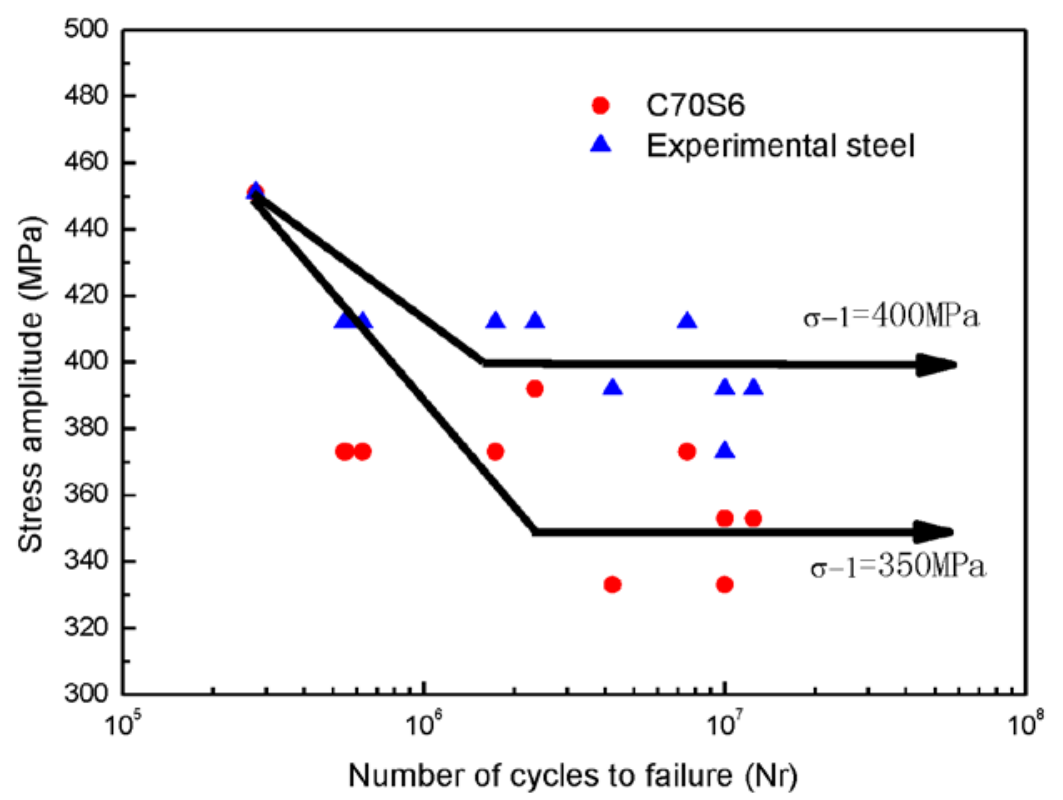

Figure 2. Fatigue limit of developed steel and C70S6 steel

\subsection{Fracture splitting properties}

The fracture splitting surfaces of developed steel were studied using SEM. The results were shown in Fig. 3. The fracture splitting surface is even without dimple and necking in the core, which shows distinct brittle fracture character (Fig. $3 c$ and $3 d$ (indicated by the arrows in fig. $3 b$ )).

One of the properties require for the fracture splitting connecting rods is that shape and dimension of the connecting rod after assembly do not change during processing. Moreover, it is required to have 
a precise positioning within microns by facing the fracture surface to assemble the cap and the rod. Therefore, the fracture surface is required to undergo brittle fracture. According to the fracture splitting surface of the developed steel, it is easy to obtain a brittle fracture.

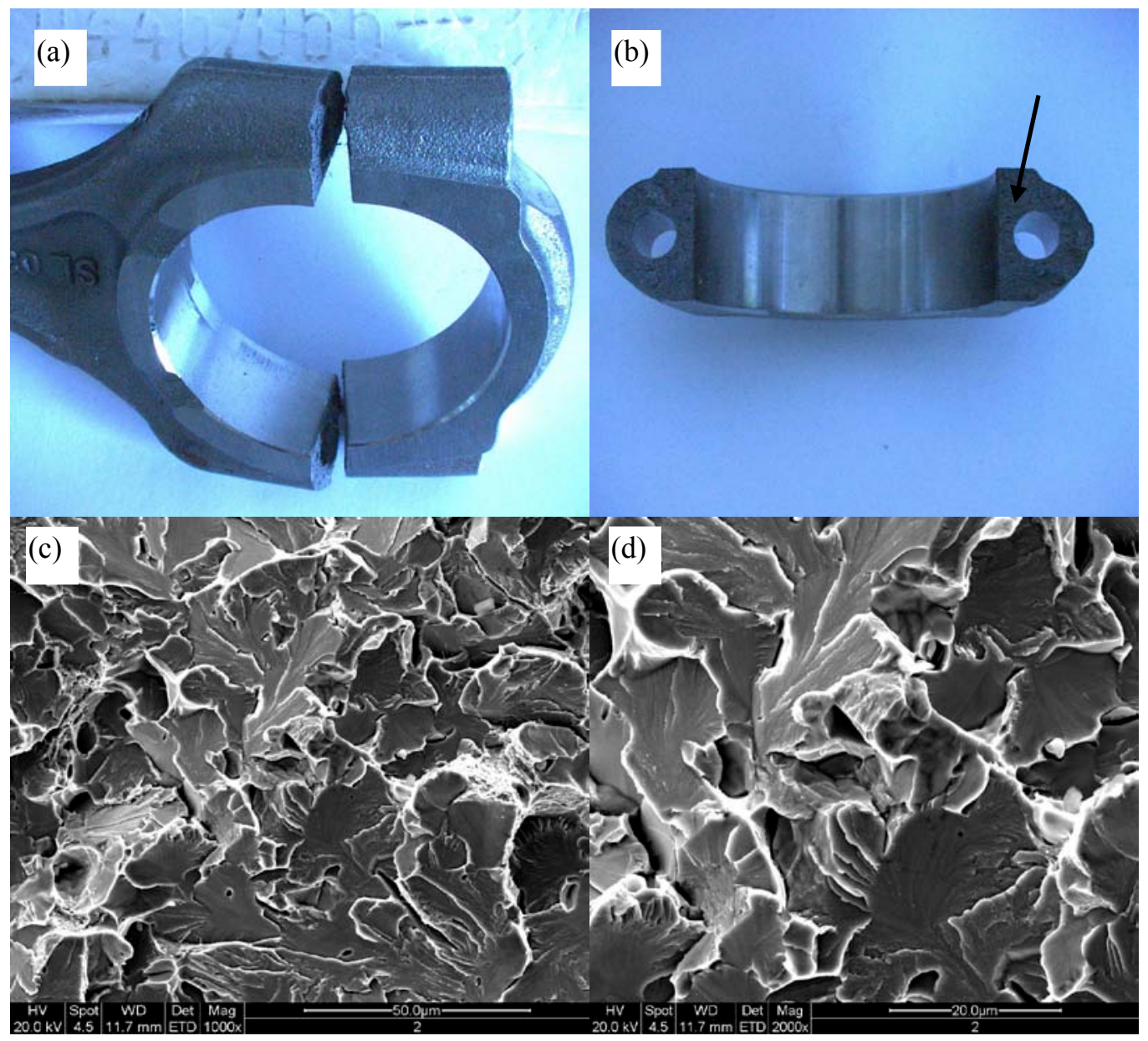

Figure 3. SEM of fracture splitting surfaces of developed steel

\section{Conclusions}

By chemical composition and process design, the developed V-N microalloyed steel has the followed character:

(1)The development microalloyed steel was composed of ferrite and pearlite, a network of ferrite was benefit to fracture splitting.

(2)Compare with C70S6 which normally used in fracture splitting rods, the developed microalloyed steel was superior in mechanical properties and fatigue strength.

(3)The fracture splitting surface showed distinct brittle fracture character and favorable fracture splitting properties.

\section{References}

1. M.Weber. SAE Technical Paper 910157, 1(1991)

2. B.Repgen. SAE Technical Paper 980882, 23(1998) 
3. Z.Gu, S.Yang, S.Ku, Y.Zhao, X. Dai, et al. Int J Adv Manuf Technol, 25, 883(2005)

4. M.Cristinacce, P.E.Reynolds, D.J.Milbourn, et al. Second International Symposium on Microalloyed Bar and Forging Steel. Colorado: Colorado School of Mines, 1(1996)

5. W.Roberts, A.Sabdberg, T.Siwecki, et al. Proc. Conf. Vanadium Steels. Krakow, Vaniter, D1(1980)

6. S.Zajac, T.Siwecki, M.korchynsky, et al. R.Asfahani,G.Tither eds. Proc. Conf. Low Carbon Steels for the 90's. ASM/TSM Materials Week, Pittsburgh, USA, 139(1993)

7. R.Lagneborg, T.Siwecki, S.Zajac, B.Hutchinson, et al. Scandinavian Journal of Metallurgy, 28, 186(1999) 